\title{
Study on Corticosteroids use Pattern in Dermatological Practice and Investigating Adverse Effect of Corticosteroids Including its Associated Factors
}

\author{
Shakya Shrestha $S,{ }^{1,2}$ Bhandari $M{ }^{1}$ Shrestha $R,{ }^{1,2}$ Thapa $S R,{ }^{1}$ Karki $A,{ }^{1}$ Prajapati $M,^{1}$ \\ Shrestha $S,{ }^{1} \mathrm{KC} \mathrm{S}^{3}$ Karna $\mathrm{D}^{3}$
}

\author{
Corresponding Author \\ Sony Shakya Shrestha \\ Department of Pharmacology \\ School of Medical Sciences, Kathmandu University \\ Dhulikhel, Kavre, Nepal. \\ E-mail: sonyshakya@hotmail.com
}

Citation

Shakya Shrestha S, Bhandari M, Shrestha R, Thapa SR, Karki A, Prajapati M, Shrestha S, KC S, Karna D. Study on Corticosteroids use Pattern in Dermatological Practice and Investigating Adverse Effect of Corticosteroids Including its Associated Factors. Kathmandu Univ Med J 2015;51(3):261-7.

\begin{abstract}
Background

Corticosteroids are highly effective drugs with anti-inflammatory and immunosuppressive properties. Due to this, they have become a mainstay of pharmacotherapy in dermatology. However, improper and long term uses are associated with a number of serious adverse effects.
\end{abstract}

\section{Objective}

To investigate the corticosteroids use pattern, adverse effects and various factors associated with adverse effects in dermatological practice.

\section{Method}

A cross-sectional study was conducted in a dermatology department of tertiary care hospital. All patients using at least one corticosteroids, either topically or systemically or the combination were included in this study. Informed consent was taken from the patients and interviewed using structured questionnaire. Statistical analysis was performed by using SPSS 20 . p-value $<0.05$ was considered as statistically significant.

\section{Result}

Among the 60 participants under this study, $81.67 \%$ of them were females. The mean $( \pm S D)$ age of the patients was 31.03 years $( \pm 15.0)$. A majority $(58.30 \%)$ of the patients was prescribed with topical corticosteroids with low potency $(25 \%)$. Most of them had used corticosteroids for urticaria. Adverse effects were reported by $33.30 \%$ of the patients. The most common adverse effect reported was the shedding of skin. Adverse effects was significantly associated with gender; use of systemic corticosteroids; regular use of corticosteroids; discontinuation of dose abruptly; and missed dose. However, there was no significant association between adverse effects and the duration of use of corticosteroids.

\section{Conclusion}

In conclusion, the present study suggested that the proper counselling and clear instruction regarding the use of corticosteroid should be provided to the patients for avoiding the abrupt discontinuation of the prescribed medication leading to treatment failure.

\section{KEY WORDS}

Adverse effect, corticosteroid, dermatology, treatment failure. 


\section{INTRODUCTION}

Corticosteroids have been a mainstay of pharmacotherapybecause of their anti-inflammatory and immunosuppressive properties in dermatological practice. ${ }^{1}$ According to the severity of the underlying condition, anatomic location of application and patient age, corticosteroids of different potencies are prescribed either in topical or systemic routes. ${ }^{2}$ They are highly effective, however, their improper and long-term use are associated with a number of serious adverse effects. ${ }^{3}$ The amount and potency of corticosteroid which is prescribed, dispensed and applied should be considered carefully because too little steroid can lead to a poor response, and too much can increase the risk of adverse effects. ${ }^{4}$ It has now been well established that rational use of these drugs can minimize the adverse effects associated with them. ${ }^{5}$ Therefore, in order to achieve the optimum benefit with least adverse effects, safe and effective use of these agents is very crucial. ${ }^{6}$ This requires various factors to be considered while prescribing, including the nature of the disease, knowledge of their mechanism of action, age of the patient, site affected, their pharmacology like potency, frequency of use and duration and other potential complicating factors. ${ }^{6}$ So, the role of intermittent monitoring of drug use pattern has been emphasized in today's clinical practice. ${ }^{7}$ Without a precise knowledge of how drugs are being prescribed and used and different factors associated with them, it is difficult to suggest measures to improve the prescribing as well as drug use habits. ${ }^{8}$

To date, data on corticosteroids use pattern, adverse effects and various factors associated with adverse effects in dermatological practice in Nepal is not reported. Hence by undertaking the present study we sought to study the various parameters related to the use and adverse effects of corticosteroids in the patients. This will help to identify the possible adverse effects associated with their use and the related factors precipitating adverse effects.

\section{METHODS}

A cross sectional study was conducted in Dhulikhel Hospital, Kathmandu University Hospital, Dhulikhel. An ethical approval was taken from Institutional Review Committee, Kathmandu University School of Medical Sciences (IRC/ KUSMS). All patients using at least one corticosteroids, either topically or systemically or their combination, who came to dermatology department satisfying inclusion criteria were included in the study. The inclusion criteria were; a) all the patients who were willing to give informed consent, attending dermatology department, b) patients using at least one corticosteroids at the time of data collection and c) patients who, at some point of time had started using corticosteroids but discontinued the medicines on their own in spite of the medical recommendations to continue the drugs.

Patients who met the inclusion criteria were informed about the study being done and about their contribution in this study. After taking informed consent from the patients, they were directly interviewed using structured questionnaire. The information regarding age, gender, education, occupation etc were recorded. Further information related to the pattern of use of corticosteroids like name of the drugs, duration of use, routes of administration, purpose of use, frequency of use, missing drug and its frequency, reasons for missing dose, adverse effects, discontinuation and its procedure etc were recorded and filled in the structured questionnaire.

The obtained information was entered into Statistical Package for Social Sciences (spss) Version 20. Statistical analysis was performed by applying Chi-square test using spss 20. p-value < 0.05 was considered as statistically significant.

\section{RESULTS}

A total of 60 patients got enrolled in this study, out of which 49 were female and 11 were male. Mean $( \pm S D)$ age of the patients was 31.03 years $( \pm 15.0)$. Majority of the patients $(n=35(58.30 \%))$ have used topical corticosteroids, $16(26.70 \%)$ have used corticosteroids by systemic route and $9(15 \%)$ have used corticosteroids by both systemic and topical routes. Among topical corticosteroids users, majority of patients $(n=15)$ have used low potency corticosteroids followed by high potency corticosteroids $(n=13)$. The details of the pattern of use of different corticosteroids are shown in Figure 1.

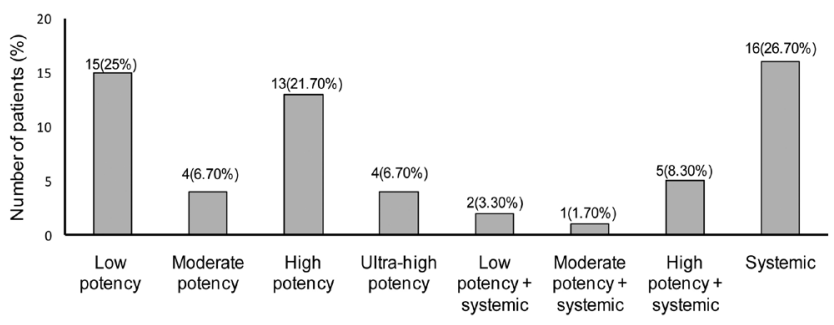

Figure 1. Bar diagram showing different corticosteroids used by 60 patients.

Majority of the patients 35 (58.30\%) have used corticosteroids for the first time followed by 15 (25\%) patients who were using them regularly and 10 (16.70\%) patients used often. Regarding duration of use, 28 $(46.70 \%)$ patients have used corticosteroids for $\leq 2$ weeks and $32(53.30 \%)$ patients have used for $>2$ weeks. Most of the patients $(n=10(16.70 \%))$ were prescribed with corticosteroids for urticaria. The details are shown in Table 1. 
Table 1. Corticosteroid use pattern among 60 patients.

\begin{tabular}{|c|c|}
\hline Characteristics & No. of Patient (\%) \\
\hline \multicolumn{2}{|l|}{ Frequency of use of corticosteroids } \\
\hline First time & $35(58.30)$ \\
\hline Often & $10(16.70)$ \\
\hline Regularly & $15(25.00)$ \\
\hline \multicolumn{2}{|l|}{ Duration of use corticosteroids } \\
\hline$\leq$ & $28(46.70)$ \\
\hline$>$ & $32(53.30)$ \\
\hline \multicolumn{2}{|l|}{$\begin{array}{l}\text { Conditions in which corticosteroids were } \\
\text { prescribed }\end{array}$} \\
\hline Urticaria & $10(16.70)$ \\
\hline Dermatitis & $9(15.00)$ \\
\hline Seborrehic dermatitis & $3(5.00)$ \\
\hline Hyperpigmented macules & $2(3.30)$ \\
\hline Photosensitivity & $8(13.30)$ \\
\hline Psoriasis & $2(3.30)$ \\
\hline Lichen Planus & $3(5.00)$ \\
\hline Acne & $8(13.30)$ \\
\hline Vitiligo & $2(3.30)$ \\
\hline Systemic lupus erythematous & $4(6.70)$ \\
\hline Plaque & $2(3.30)$ \\
\hline Miscellaneous* & $7(11.70)$ \\
\hline Patients who have ever missed corticosteroids & $17(28.34)$ \\
\hline \multicolumn{2}{|l|}{ Missing Frequency ( $n=17)$} \\
\hline Rare & $15(88.24)$ \\
\hline Often & $2(11.76)$ \\
\hline \multicolumn{2}{|l|}{ Reasons for missing corticosteroids } \\
\hline Forgetfullness & $15(88.24)$ \\
\hline Carelessness & $2(11.76)$ \\
\hline $\begin{array}{l}\text { Patients who have ever discontinued cortico- } \\
\text { steroids }\end{array}$ & $34(56.67)$ \\
\hline \multicolumn{2}{|l|}{ Discontinued method $(n=34)$} \\
\hline Dose tapering & $7(20.59)$ \\
\hline Abruptly & $27(79.41)$ \\
\hline \multicolumn{2}{|l|}{$\begin{array}{l}\text { Reason of discontinuation of corticosteroids } \\
(n=434)\end{array}$} \\
\hline Relief of symptoms & $25(73.54)$ \\
\hline More deterioration of symptoms & $2(5.88)$ \\
\hline No benefit & $5(14.70)$ \\
\hline Others** & $2(5.88)$ \\
\hline
\end{tabular}

Among corticosteroids users in this study, 17 (28.30\%) of them have missed the drug, out of which 15 (88.24\%) have missed the dose rarely and 2 (11.76\%) have missed often. Forgetfulness 15 (88.24\%) was the major reason for missing the dose followed by carelessness 2 (11.76\%). Out of 34 patients who have discontinued the drug, 7 (20.59\%) have followed dose tapering method whereas 27 (79.41\%) of patients have discontinued the drug abruptly.
The most common reason 25 (73.54\%) for discontinuation of corticosteroids was mentioned as relief of symptoms. The details of the corticosteroids use pattern are shown in Table 1.

Regarding adverse effects of corticosteroids, 20 (33.30\%) of patients have reported adverse effects. The most common adverse effect reported by patients was shedding of skin 7 (35\%). The details of adverse effects reported are shown in Figure 2.

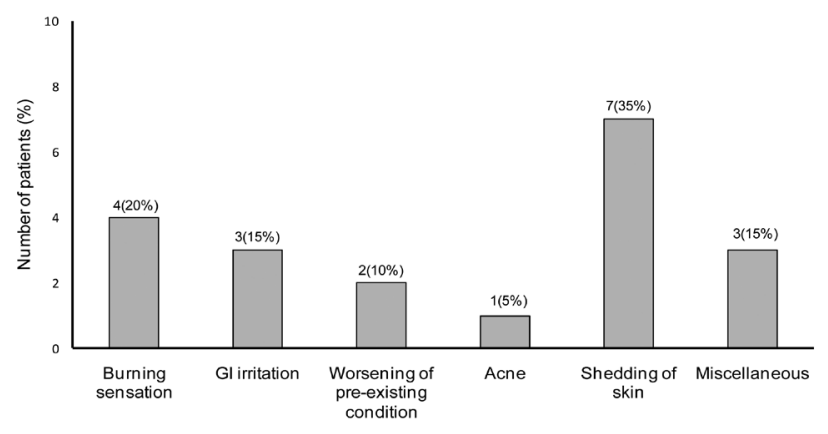

Figure 1. Bar diagram showing adverse effects shown by use of corticosteroids. Miscellaneous includes various conditions like Menstruation irregularities, hyperglycemia, swelling of face.

In the present study, adverse effects were seen in significantly higher number of female patients $(p<0.039)$. Significant association was found between the adverse effects seen in patients with use of systemic corticosteroids $(p<0.05)$. Similarly, adverse effects were reported by significantly higher number of patients who were using corticosteroids on the regular basis $(p<0.05)$ and was less common in those patients who never used to miss dose $(p<0.058)$. Furthermore, our study revealed that significantly higher number of patients who had adverse effects discontinued corticosteroids abruptly $(p<0.05)$. However, no statistical association was found between adverse effects seen in patients with duration of use of corticosteroids (Table 2).

\section{DISCUSSION}

Corticosteroids constitute one of the largest groups of drugs which are being used in dermatological practice as a short term as well as long term therapy that are associated with a number of adverse effects. ${ }^{7}$ Their rational use can however, minimize the systemic and cutaneous side effects that occur with corticosteroids. ${ }^{7}$ Physicians ought to prescribe the corticosteroid that will treat the dermatological condition with maximum therapeutic benefits and least possible adverse effects. ${ }^{7}$

In the present study, higher number of corticosteroids users was female. In consistence with the findings of our study, previous study has also reported that higher numbers of females were prescribed with corticosteroids along with antimicrobials for different dermatological conditions. ${ }^{9}$ 
Table 2. Demographic and other characteristics of 60 patients with reference to adverse effects.

\begin{tabular}{|c|c|c|c|c|}
\hline Variables & $\begin{array}{l}\text { Total } \\
\text { (n) }\end{array}$ & $\begin{array}{l}\text { Adverse ef- } \\
\text { fects }(n=20) \\
\text { No. }(\%)\end{array}$ & $\begin{array}{l}\text { No adverse } \\
\text { effects } \\
(n=40) \\
\text { No. }(\%)\end{array}$ & p-value \\
\hline \multicolumn{5}{|l|}{ Gender } \\
\hline Male & 11 & $1(9.10)$ & $10(90.90)$ & \multirow{2}{*}{0.039} \\
\hline Female & 49 & 19 (38.77) & $30(61.23)$ & \\
\hline \multicolumn{5}{|c|}{ Different potences of corticosteriods and combinations used } \\
\hline Low potency & 15 & $6(40.00)$ & $9(60.00)$ & \multirow{8}{*}{0.002} \\
\hline Moderate potency & 4 & $0(0.00)$ & $4(100.00)$ & \\
\hline High potency & 13 & $1(7.69)$ & $12(92.31)$ & \\
\hline Ultra high potency & 4 & $0(0.00)$ & $4(100.00)$ & \\
\hline $\begin{array}{l}\text { Low potency + } \\
\text { systemic }\end{array}$ & 2 & $2(100.00)$ & $0(0.00)$ & \\
\hline $\begin{array}{l}\text { Moderate potency } \\
\text { + systemic }\end{array}$ & 1 & $0(0.00)$ & $1(100.00)$ & \\
\hline $\begin{array}{l}\text { High potency + } \\
\text { systemic }\end{array}$ & 5 & $1(20.00)$ & $4(80.00)$ & \\
\hline Systemic & 16 & $10(62.50)$ & $6(37.50)$ & \\
\hline \multicolumn{5}{|c|}{ Frequancy of use of corticosteroids } \\
\hline First time & 35 & $6(17.14)$ & $29(82.86)$ & \multirow{3}{*}{0.006} \\
\hline Often & 10 & $5(50.00)$ & $5(50.00)$ & \\
\hline Regularly & 15 & $9(60.00)$ & $6(40.00)$ & \\
\hline \multicolumn{5}{|c|}{ Duration of use of corticosteroids } \\
\hline$\leq 2$ weeks & 28 & $6(21.43)$ & $22(78.57)$ & \multirow{2}{*}{0.067} \\
\hline$>2$ weeks & 32 & $14(33.35)$ & $18(56.25)$ & \\
\hline \multicolumn{5}{|l|}{ Missed Dose } \\
\hline Yes & 17 & $9(52.94)$ & $8(47.06)$ & \multirow{2}{*}{0.043} \\
\hline No & 43 & $11(25.58)$ & $32(74.42)$ & \\
\hline \multicolumn{5}{|c|}{ Discontinuation procedure } \\
\hline Not Discontinued & 26 & $4(15.38)$ & $22(84.62)$ & \multirow{3}{*}{0.016} \\
\hline Dose tapering & 7 & $2(28.57)$ & $5(71.43)$ & \\
\hline Abruptly & 27 & $14(51.85)$ & $13(18.15)$ & \\
\hline
\end{tabular}

The high number of females using corticosteroids for dermatological purposes might be due to women being more conscious about the health of their skin. Additionally, women outnumber men in using cosmetics, which might have especially, predisposed them to a number of skin disorders. The present study has revealed that patients in age above 30 years were using corticosteroid which is similar to the previous study showing patients belonging to age below 40 years. ${ }^{9}$ This finding strongly supports the fact that people at this age become more conscious about their physical appearance from cosmetic point of view.

A majority of the patients in this study used topical corticosteroids followed by systemic corticosteroids. A very few number of the patients used corticosteroids by both the topical and systemic routes. Our finding is in consistence with several other studies where topical corticosteroids were preferred over systemic corticosteroids for dermatologic disorders. ${ }^{7,10-12}$ This might be due to the effectiveness of topical corticosteroids in many non-infective skin disorders and the fact that they are safer to use for acute skin diseases. ${ }^{7,13}$ Although topical corticosteroids are relatively safe, they can more frequently produce local adverse effects and rarely systemic effects when used inappropriately. ${ }^{13,14}$ Systemic corticosteroids, however, are required for prolonged periods, as in atopic dermatitis so they have to be tapered or reduced to minimal doses for the long term therapy which makes them less preferred in many other dermatologic disorders. ${ }^{9}$

On the other hand, among the topical corticosteroid users, higher number of patients was prescribed with low potency corticosteroids. It might be because of minimal risk of adverse effects associated with low potency corticosteroids. Furthermore, it has been suggested that low potency corticosteroids are the safest for long term use and can be applied over large surface of the body and on children and elderly as well. ${ }^{15,16}$ However, in certain conditions like atopic dermatitis, high potency corticosteroids have been preferred over low and moderately potent corticosteroids as they have shown to reduce the density of $\mathrm{S}$. aureus in such condition. ${ }^{17}$

A majority of the patients under this study used corticosteroids for the first time followed by those using it regularly. A study suggests that the optimum dosing schedule of the steroids should have minimum frequency of application and still provide relief. ${ }^{4}$ Further, the study suggests that the application of the steroids should be monitored carefully as too little application can lead to a poor response while too much can increase the occurrence of side effects. ${ }^{4}$ Additionally, the shortest possible treatment course is recommended for acute skin diseases. ${ }^{13}$ Likewise, the study also suggests that treatment for such skin conditions should not last longer than two weeks on the face and three to four weeks on the rest of the body. ${ }^{13}$ In contrast, a majority of the patients under the current study had used corticosteroids for more than two weeks. Another study on patients with actinic keratosis suggests that treatment duration exceeding four weeks significantly influences non-adherence. ${ }^{18}$ Therefore, for longer treatment periods, intermittent therapy such as every other day, once a week application or a gap of 1-2 weeks in between the cycles has been suggested that might help to reduce the occurrences of adverse effects. ${ }^{13}$

Most of the patients in this study had used corticosteroids for urticaria followed by other conditions such as dermatitis, photosensitivity, acne, and others. Similarly, another study reported that topical corticosteroids were mainly used for treating non-infective dermatologic disorders associated with inflammation such as psoriasis, atopic dermatitis, contact dermatitis and otitis externa. ${ }^{7}$ Corticosteroids have been prescribed, most commonly, in psoriasis and also in adult atopic dermatitis and nummular eczema. ${ }^{13}$

The present study showed that about a quarter of patients have missed the dose and majority had never missed the 
dose. Consistent with our findings, another study in patients with actinic keratosis reported higher levels of adherence to a once-a-day topical corticosteroid therapy, although rates of adherence declined over the treatment period. ${ }^{19}$ On contrary, adherence to topical therapy regimens was found to be low for a range of skin conditions, especially chronic skin disorders such as psoriasis which require a long-term treatment. ${ }^{20,21}$ Similarly, another study reported that approximately $40 \%$ of the patients with psoriasis did not use treatments as per the direction of physician. ${ }^{22}$

Our study has revealed that the majority of the patients had missed dose due to forgetfulness. Carelessness was another additional reason for missing the prescribed dose in lesser number of patients. Supporting our findings, a previous study has reported that forgetting to take dose accounts for around $40 \%$ of non-adherence. ${ }^{18}$ Additionally, younger age of the patient, the cosmetic characteristics of treatment, the complexity of treatment regimen, frequency of use, treatment duration, and fear of, or occurrence of adverse effects also contribute to non-adherence to medication in many skin disorders. ${ }^{18,20}$ Moreover, the vehicle used in treating skin disorders such as ointment is greasy and difficult to spread, which makes it cosmetically unappealing, leading to patient's poor adherence to treatment. ${ }^{13}$

Among the patients who had discontinued the drug, a majority of them had discontinued the drug abruptly whereas a few patients followed dose tapering method. Similar finding was reported by Shergill et al. where patients with actinic keratosis either forgot to use their treatment or intentionally chose not to apply treatment as per suggestions, and discontinued the medication abruptly. ${ }^{18}$ Corticosteroids tapering is essential to avoid persistent dermatological condition, exacerbating the condition and prevent withdrawal symptoms from occurring. ${ }^{23}$

In the present study, a one third of the patients reported adverse effects. The most common adverse effect reported was the shedding of skin followed by burning sensation, GI irritation, worsening of pre-existing condition, acne, and others such as menstrual irregularities, hyperglycaemia, and swelling of face. In consistent with the findings of our study, several other studies have reported various systemic and cutaneous adverse effects with corticosteroids use. ${ }^{4,7,9,13}$ Skin atrophy has been reported as the most common adverse effect of topical corticosteroids along with many other reactions such as hypersensitivity, percutaneous absorption and tachyphylaxis., ${ }^{4,9,13}$ In contrary to the findings of previous studies, in our study, shedding of skin was the most commonly reported adverse effect which might be the consequence of withdrawal from corticosteroids. ${ }^{24}$ Topical corticosteroids are known to decrease skin elasticity and bring alterations in its mechanical properties. ${ }^{25}$ Burning sensation was the second commonly reported adverse effect in this study which might be due to contact hypersensitivity to topical corticosteroids upon prolonged exposure. ${ }^{25}$ However, contact hypersensitivity to corticosteroids must be differentiated from hypersensitivity to other constituents/ excipients in the formulation e.g. lanolin, parabenes, antibiotics. ${ }^{25}$ Another adverse effect reported by patients enrolled in this study was gastrointestinal irritation which might be the systemic effect of corticosteroids as suggested by other studies. ${ }^{26,27}$ Corticosteroid therapy can even lead to gastrointestinal bleeding and perforation which is more risky when given with non-steroidal anti-inflammatory drugs as reported by other studies. ${ }^{28,29}$ Worsening of pre-existing condition has also been reported in this study as reported by several other studies. ${ }^{30,31}$ It has been related with either overuse of corticosteroids or aggravation of cutaneous infection depending on their use in various dermatological conditions. ${ }^{30,31}$ However, this could not be analysed from the current study as it was a mono-centred study with a limited sample size. Acne is another adverse effect reported by the patients in our study which is consistent to the findings of previous studies in which topical corticosteroids rapidly induced an acneiform eruption. ${ }^{25,30,31}$ It has been suggested that the acnegenic effect of topical corticosteroids might be due to the degradation of the follicular epithelium which results in extrusion of the follicular content. ${ }^{25,30,31}$ Corticosteroid-induced acne might be due to application of high concentration of drugs, application under occlusion, application to acne-prone areas of face and upper back etc., as proposed by another study. ${ }^{25}$ However, these predisposing factors were not assessed by our study as to assess such factors is beyond the scope of the present study and this warrants for further multi-centred study with a large sample size. In the present study, adverse effects were significantly high in females. This might be due to the higher number of females being prescribed with corticosteroids for skin disorders which was consistent to the findings of previous study. ${ }^{9}$ Additionally, adverse effects were significantly associated with the use of systemic corticosteroids than topical corticosteroids. In agreement to the finding of our study, even low doses of systemic corticosteroids used for prolonged periods, was associated with significant morbidity and mortality. ${ }^{23}$

Multiple complications such as osteoporosis, delayed wound healing, cutaneous effects including purpura, atrophy, striae, hirsutism, alopecia, hyper/hypopigmentation, facial plethora, and fat redistribution causing the classic "buffalo hump" on the upper back were reported with long-term use of systemic corticosteroids. ${ }^{23,32}$ Topical corticosteroids, which are considered relatively safe, are also associated with various adverse effects as discussed above though they are preferred over systemic corticosteroids for dermatologic disorders. ${ }^{7,10-12}$ Our study revealed that adverse effects were significantly associated with the regular use of corticosteroids. This finding is in strong agreement with several other studies in which incidence of adverse effects were high with daily and long-term use of corticosteroids like increase in risk of bone fractures, restlessness, insomnia, mania, depression, cognitive defects, weight 
gain, thinning of skin etc. ${ }^{23,32-36}$ It has been suggested that more frequent administration of steroids does not help improve the condition rather its chronic application can induce tolerance and tachyphylaxis. ${ }^{4}$ Additionally, our study found that adverse effects were significantly less common in patients who never missed the prescribed dose. Likewise, another study has suggested that topical corticosteroids when used incorrectly, either missing the prescribed dose or withdrawing abruptly can produce more frequent local adverse effects and an occasional systemic effects. ${ }^{13}$ Consistent to our findings, another study has also reported that the risk of osteoporosis, one of the most serious complications in patients receiving long-term corticosteroid therapy, was highly related to the daily corticosteroid dose which worsened upon incomplete medication. ${ }^{37}$ Although, the adverse effects encountered with corticosteroids use is bothersome, it is more likely that the patients following the appropriate and prescribed dosage regimen will have less adverse effects as suggested by previous studies. ${ }^{13,37}$ Furthermore, our study found that a significantly higher number of patients in whom adverse effects were seen had discontinued corticosteroids abruptly. It might be because of the occurrence of withdrawal symptoms or relapse of underlying disease or aggravation of corticosteroids induced adverse effects on stopping the drug abruptly as suggested by other studies. ${ }^{38-40}$ Such symptoms are seen when topical corticosteroids are used for longer duration, generally $>2$ weeks and/or given in high doses and stopped abruptly. ${ }^{38-40}$ However, in this study, though higher number of patients in whom adverse effects were seen had used corticosteroids for $>2$ weeks, there was no significant association between them. This reinforces for further multi-centred prospective study in a large sample size. Nevertheless, rapid reduction or abrupt withdrawal from corticosteroids therapy should be avoided.

\section{CONCLUSION}

Corticosteroid therapy is of fundamental importance in clinical, especially in dermatological practice. Despite their effectiveness, their inappropriate and prolonged use in various dermatological conditions predisposes a patient to a number of adverse effects, ranging from mild to severe. It is extremely important that patients are correctly educated and instructed for corticosteroid use and properly counselled for the possible adverse effects with their improper use.

\section{REFERENCES}

1. Sweileh WM. Audit of prescribing practices of topical corticosteroids in outpatient dermatology clinics in north Palestine. Eastern Mediterranean Health Journal 2006;12:161-9.

2. Tadicherla S, Ross K, Shenefelt PD, Fenske NA. Topical corticosteroids in dermatology. J Drugs Dermatol 2009;8(12):1093-1105.

3. Schoepe S, Schacke H, May E, Asadullah K. Glucocorticoid therapyinduced skin Atrophy. Exp Dermatol 2006;15:406-20.

4. Ference JD, Last AR. Choosing Topical Corticosteroids. Am Fam Physician 2009;79:135-40.

5. Sharma SC, Uppal R, Sharma PL, Kaur S. Rational Use of Topical Corticosteriods in Dermatology. Indian J Pharmacol 1990;22:141-4.

6. Lee $\mathrm{M}$, Marks R. The role of corticosteroids in dermatology. Aust Prescr 1998;21:9-11.

7. Ashok Kumar M, Noushad PP, Shailaja K, Jayasutha J, Ramasamy C. A study on drug prescribing pattern and use of corticosteroids in dermatological conditions at a tertiary care teaching hospital. International Journal of Pharmaceutical Sciences Review and Research 2011;9:132-5.

8. WHO. Introduction to Drug Utilization Research. Geneva. 2003.

9. Sarkar C, Das B, Sripathi H. Drug prescribing pattern in dermatology in a teaching hospital in western Nepal. JNMA 2001;41:241-6.

10. Arellano FM, Wentworth CE, Arana A, Fernández C, Carle PF. Risk of Lymphoma Following Exposure to Calcineurin Inhibitors and Topical Steroids in Patients with Atopic Dermatitis. Journal of Investigative dermatology 2007;127:808-16.

11. Joly P, Roujeau JC, Benichou J, Picard C, Dreno B, Delaporte E, Vaillant L, D'Incan M, Plantin P, Bedane C, Young P, Bernard P. Group A Comparison of Oral and Topical Corticosteroids in Patients with Bullous Pemphigoid. N Eng/ J Med 2002; 346:321-7.

12. Schaefer ET, Fitzgerald JF, Molleston JP, Croffie JM, Pfefferkorn $M D$, Corkins MR, et al. Comparison of Oral Prednisone and Topical Fluticasone in the Treatment of Eosinophilic Esophagitis: A Randomized Trial in Children. Clinical Gastroenterology and Hepatology 2008;6:2165-73.

13. Giuliana $C$, Uribe P, Fernández-Peñas P. Rational use of topical corticosteroids. Aust Prescr 2013;36:158-61.

14. Bewley A and Dermatology Working Group. Expert consensus: time for a change in the way we advise our patients to use topical corticosteroids. British Journal of Dermatology 2008;158:917-20.

15. Horn EJ, Domm S, Katz HI, Lebwohl M, Mrowietz U, and Kragballe K. Topical corticosteroids in psoriasis: strategies for improving safety. Journal of the European Academy of Dermatology and Venereology 2010;24:119-24.

16. Nast A, Kopp IB, Augustin M, Banditt KB, Boehncke WH, Follmann M et al. Evidence-based (S3) guidelines for the treatment of psoriasis vulgaris. Journal der Deutschen Dermatologischen Gesellschaft 2007;5:1-119.

17. Eskil J. Nilsson, Claes G. Henning, Jelena Magnusson. Topical corticosteroids and Staphylococcus aureus in atopic dermatitis. Journal of the American Academy of Dermatology 1992;27:29-34. 
18. Shergill B, Zokaie S, Carr AJ. Non-adherence to topical treatments for actinic keratosis. Patient Preference and Adherence 2014;8:35-41.

19. Yentzer B, Hick J, Williams L, Inabinet R, Wilson R, Camacho FT, et al. Adherence to a topical regimen of 5-fluorouracil, $0.5 \%$ cream for the treatment of actinic keratosis. Arch Dermatol 2009;145(2):203-5.

20. Devaux S, Castela A, Archier E, Gallini A, Joly P, Misery L, et al. Adherence to topical treatment in psoriasis: a systematic literature review. J Eur Acad Dermatology and Venereol 2012;3:61-7.

21. Lee IA, Maibach HI. Pharmionics in dermatology: a review of topical medication adherence. Am J ClinDermatol 2006;7(4):231-6.

22. Feldman SR, Horn EJ, Balkrishnan R, et al. International Psoriasis Council. Psoriasis: improving adherence to topical therapy. J Am Acad Dermatol. 2008;59(5):1009-16.

23. MitsosL and Sasseville D. Systemic Corticosteroid Use in Dermatology: Defining, Detailing, and Demystifying. Dermatology Rounds 2011; 7:124-135.

24. Rapaport MJ, Lebwohl M. Corticosteroid addiction and withdrawal in the atopic: The red burning skin syndrome. Clin Dermatol 2003;21:201-14.

25. Hengge UR, Ruzicka T, Schwartz RA, Cork MJ. Adverse effects of topical glucocorticosteroids. J Am Acad Dermatol 2006;54:1-15.

26. Messer J, Reitman D, Sacks HS, Smith H, Chalmers TC. Association of adrenocorticosteroid therapy and peptic- ulcer disease. N Engl J Med 1983;309:21-4.

27. Piper JM, Ray WA, Daugherty JR, Griffin MR. Corticosteroid use and peptic ulcer disease: role of nonsteroidal anti-inflammatory drugs. Ann Intern Med 1991;114:735-740.

28. Aucott JN. Glucocorticoids and infection. Endocrinol Metab Clin North Am 1994;23:655-70.

29. Schwartz RA. Superficial fungal infections. Lancet 2004;364:1173-82.
30. Kaidbey KH, Kligman AM. The pathogenesis of topical steroid acne. J Invest Dermatol 1974;62:31-6.

31. Litt JZ. Steroid-induced rosacea. Am Fam Physician 1993;48:67-71.

32. Da Silva JA, Jacobs JW, Kirwan JR, Boers M, Saag KG, Inês LB, et al. Safety of low dose glucocorticoid treatment in rheumatoid arthritis: Published evidence and prospective trial data. Ann Rheum Dis 2006;65:285-293.

33. Bernstein CN, Blanchard JF, Metge C, Yogendran M. The association between corticosteroid use and development of fractures among IBD patients in a population-based database. Am J Gastroenterol 2003;98(8):1797-801.

34. Curtis JR, Westfall AO, Allison J, Bijlsma JW, Freeman A, George V, Kovac SH, Spettell CM, Saag KG. Population-based assessment of adverse events associated with long-term glucocorticoid use. Arthritis Rheum 2006;55:420-426.

35. Wolkowitz OM, Rubinow D, Doran AR, Breier A, Berrettini WH, Kling MA. Prednison effects on neurochemistry and behavior. Preliminary findings. Arch Gen Psychiatry 1990;47:963-8.

36. Hurren J. Minerva. British Medical Journal 1996; 313:1024.

37. van Staa TP, Leufkens HGM, Abenhaim L, Zhang B and Cooper C. Oral corticosteroids and fracture risk: relationship to daily and cumulative doses. Rheumatology 2000;39:1383-9.

38. CrésioAlves, Teresa Cristina Vicente Robazzi, Milena Mendonça. Withdrawal from glucocorticosteroid therapy: clinical practice recommendations. J Pediatr (Rio J) 2008;84(3):192-202.

39. Krasner AS. Glucocorticoid- induced adrenalin sufficiency. JAMA 1999;282:671-6.

40. Shulman DI, Palmert MR, Kemp SF; Lawson Wilkins Drug and Therapeutic Committee. Adrenal insufficiency: still a cause of morbidity and death in childhood. Pediatrics 2007;119:484-94. 